lationship of external surroundings to the spread of tubercular disease. The author pointed out the unsatisfactory nature of statistics upon this subject, owing to the complexity of apparently simple factors. Constant attendance upon phthisical patients in badly ventilated rooms, and certain occupations giving rise to irritation of respiratory tract from dust, metallic or otherwise, were however, according to the lecturer, potent factors in the spread of tuberculosis. Papers followed upon tubercular disease among various employés, notably knife and sword makers, bookbinders, compositors, and cigar makers.

Section II.-Aetiology.-This Section was opened by Prof. Flügge (Breslau), who read a well-appreciated paper upon the relation of the tubercle bacillus to tuberculosis. Recent work has not in this connection modified to any extent the dicta originally enunciated by Koch The tubercle bacillus is the immediate cause of tuberculosis, and arises in practically all cases from a tuberculous animal. Its parasitic nature is obligatory, i.e. except in the case of artificial cultures the bacillus cannot develop outside the animal organism. By means of artificial cultures it is possible to modify the tubercle bacillus in certain ways, notably with regard to its morphological character, and its virulence. Prof. C. Fränkel (Halle) discoursed eloquently upon the nature and modus operandi of tubercular infection. $\mathrm{He}$ pointed out that outside the animal body tubercle bacill die in from six to seven months, the important factors in killing them being light, and the fact that they lose their water by evaporation, and with it their life. As a result of this it is, as a rule, only the immediate neighbourhood of the patient, from $\mathrm{I}$ to $\mathrm{I} \frac{1}{2}$ metre, that is infective. Infection usually takes place through the infected person inhaling fresh and moist tubercle bacilli which ("infected drops") have been ejected usually during a coughing fit, also by the inhalation of dust contaminated with dried sputum. He further pointed out that man was relatively unsusceptible to tubercular infection, and that, as a rule, it was only by repeated and continued inhalation, \&c., of tubercle bacilli that infection occurred.

A subject of great interest to physicians was considered at some length by Prof. Pfeiffer (Berlin), viz. "mixed infection." Consumption, as we know it, is rarely due simply to the tubercle bacillus, but to the superadded action of other infective organisms. As many as twentyfour different varieties of bacilli have been obtained from the sputum of a phthisical patient. An important practical point brought out by the lecturer was that cases of mixed infection ought to be recognised in consumptive hospitals, and isolated, as they may be a source of danger to phthisical patients; that is, these latter may get a mixed infection superadded to their other troubles. Prof. Löffler read a short paper upon heredity, immunity and disposition in their relation to tuberculosis. Hereditary tuberculosis in the sense, for instance, of congenital syphilis, is unknown. In this disease hereditary influences probably play a relatively small part as such. Tuberculosis occurs in members of the same family, mostly because by living together the members infect each other. Prof. Löffler quoted one family as an instance of this. The father and mother, two daughters and seven sons, all died of phthisis. The family consisted of fifty-eight other members, not one of whom was tuberculous. The infection was entirely confined to the members of the family living together. The lecturer emphasised the fact that no natural immunity to tuberculosis exists. Dr. von Zander gave some aetiological statistics of tuberculosis. Out of 312 cases investigated, II6 were communicated from man to man; amongst these infection between sisters occurred the most often.

Section III.-Prophylaxis.-Dr. Roth (Potsdam) discussed certain rules for the prevention of tubercular infec- tion. These mostly consisted of measures directed to the disposal of the sputum, and the use of a cloth in front of the mouth during coughing fits, to limit the area of "infective drop" dispersion. Prof. v. Leube (Wurzburg) considered the prophylactive methods against tuberculosis in hospitals. If measures such as those mentioned above are thoroughly carried out, tubercular patients need not be isolated from the general hospital inmates. Care should be taken by attendants and nurses especially in dusting rooms, when it would be advisable for them to have their mouth and nose protected by a mask.

All members of the Congress listened most attentively to a short paper, by Prof. Virchow, upon the prevention of tuberculosis in so far as concerns food. Prof. Virchow considered four articles of diet : (I) beef, (2) pork, (3) poultry, (4) milk. Of these he regarded milk as far the most important. He advised a more careful and systematic exclusion (under central control) of tubercular meat and cattle, and the rejection of milk from all cows which reacted to the tuberculin list. Even these measures the author described as palliative, the only curative measure being the killing of all animals that reacted to the tubercular list. In this connection, Dr. Schumburg (Hannover) gave the result of his researches as to whether ordinary butcher's meat contained tubercle bacilli. The result of twenty-four inoculations (intra-peritoneal) of guinea-pigs with the juice of twelve different meat samples, was that two animals died of purulent peritonitis, two greatly diminished in weight, the remaining twenty remained well. Dr. Baer (Berlin) discussed the muchvexed question of alcohol and tuberculosis. He concludes, upon apparently very insufficient grounds, that alcohol in the consumptive sanatoria should only be used as medicine under the most urgent circumstances. Dr. Ritter read a paper upon the protection of children from tuberculosis. An interesting communication upon the diminution in the total death-rate from consumption due to modern methods of treatment was made by Dr. Julius Lehmann (Copenhagen). Dr. Kuno Obermüller discussed some interesting investigations upon the presence of the tubercle bacillus in ordinary market milk and butter. He centrifugalised the milk, and injected less than $5 \mathrm{cc}$. of the sediment into the peritoneal cavity of guineapigs. The milk was taken from a dairy which supplies Berlin with 80,000 litres daily. The result was that 30 per cent. of the injected animals died in from eleven to thirteen weeks of tuberculosis. The milk used was the best and most costly infant milk. According to the author, Berlin butter is also largely infected with virulent tubercle bacilli, which are quite distinct from the so-called butter bacillus. Dr. Hambleton, President of the Polytechnic Physical Development Society, was the author of a communication on the prevention of pulmonary tuberculosis. One of the most potent factors to this end is, according to the author, chest development, and he took this opportunity of bringing before the notice of the Congress the work of the Society in this direction. This method had, according to the author, been most successful in preventing and even arresting tuberculosis among the employés of trades having an injurious effect upon the respiratory organs.

F. W. TUNNICLIFFE.

\section{THE JUBILEE OF SIR GEORGE GABRIEL STOKES.}

$T \mathrm{HE}$ celebrations in connection with the jubilee of Sir George Gabriel Stokes, who has occupied the Lucasian Chair of Mathematics at Cambridge University since I 849 , begin this afternoon (Thursday) with the delivery by Prof. Cornu, of the École Polytechnique, Paris, of the Rede Lecture. Prof. Cornu has chosen as his subject, "The Wave Theory of Light and its Influence on Moder Physics." 
This evening a banquet will be given by Pembroke College, at which many of the distinguished guests and older colleagues of Sir George will be entertained in the hall of the College, which he entered as a freshman in 1837. During the evening the University will entertain about one thousand visitors and residents at a conversazione in the Fitzwilliam Museum, an interesting feature of which will be the presentation by Lord Kelvin of two busts, executed by Mr. Hamo Thorneycroft, of Sir George Stokes-one to the University, and the other to Pembroke College.

On Friday at II a.m., in the Senate House, the addresses of congratulation will be presented to the Vice-Chancellor, and handed by him to Sir George Stokes. Some sixty-five different institutions from all parts of the world will be represented. At 7 o'clock the delegates and their hosts will be entertained at luncheon by the Vice-Chancellor at Downing College, and at 2.45 a second congregation will be held in the Senate House, at which the Chancellor, the Duke of Devonshire, will preside. At this congregation, the honorary degree of Sc.D. will be conferred on Profs. A. Cornu and J. G. Darboux of Paris, on Prof. A. A. Michelson of Chicago, on Prof. M. G. Mittag-Leffler of Stockholm, on Prof. G. H. Quincke of Heidelberg, and on Prof. W. Voigt of Göttingen. A gold medal struck in honour of the occasion will be presented to Sir George Stokes by the Chancellor, and replicas will be sent to all the Universities and learned societies who are represented at the Jubilee.

Later in the afternoon a garden party will be held in the grounds of Pembroke College, and in the evening the University will entertain the delegates and guests at a dinner given in the hall of Trinity College. The Chancellor will take the chair, and amongst other distinguished guests who have accepted invitations may be mentioned the Lord Lieutenant of Cambridyeshire, the Bishop of Ely, the President of the Royal Society, the ViceChancellors of the Universities of Oxford, Aberdeen, and London, the Earl of Rosse, Lord Kelvin, Lord Rayleigh, L.ord Blythswood, the Provost of Trinity College, Dublin, Monsignor Molloy, and many others.

There will be a special meeting of the Cambridge Philosophical Society, at which some of the foreign members will, it is expected, read papers. This will probably take place on Monday, June 5. Many of the guests will leave Cambridge for London to take part in the anniversary celebrations of the Royal Institution.

\section{NOTES.}

A meeting for discussion will be held at the Royal Society on Thursday next, June 8 . The subject to be discussed-preventive inoculation-will be introduced by M. Haffkine.

ARRANGEMENTS for the sixty-ninth annual meeting of the British Association at Dover, in September next, are making satisfactory progress. The local committees are actively at work, and in response to the appeal of the hospitality committees over $1500 \%$. has already been subscribed. As previously announced, the president of the meeting will be Prof. Michael Foster, and the presidersts of the various sections are to be :-Mathematical and physical science, Prof. J. HI. Poynting; chemistry, Mr. Horace T. Brown; geology, Sir Archibald Geikie ; zoology, Mr. Adam Sedgwick; geography, Sir John Murray, K.C.B. ; economical science, Mr. Henry Higgs; mechanical science, Sir William H. White; anthropology, Mr. C. II. Read; physiology, Mr. J. N. Langley; botany, Sir George King, K.C.I.E. The first general meeting will be held at the Connaught Hall on Wednesday, September I3, at 8 p.m. precisely, when Prof. Michael Foster will deliver an address; on Thursday evening, September 14, at 830 p.m., there will be a soirée in the School of Art; on Friday evening, September 15, at 8.30 p.m., a discourse will be delivered by Prof. Charles Richet, on "La vibration nerveuse"; on Monday evening, September I 8 , at 8.30 p.m., a discourse will be delivered by Prof. Fleming, F.R.S., on "The Centenary of the Electric Current"; on Tuesday evening, September 19, at 8.30 p.m., there will be a soirée in the School of Art; on Wednesday, September 20, the concluding general meeting will be held at 2.30 p.m. Excursions to places of interest in the neighbourhood of Dover and to the continent will be made on Thursday, September 2I. Members of the Association Française pour l'Avancement des Sciences will visit Dover on Saturday, September I6. Members of the British Association are invited to visit Boulogne on Thursday, September 21.

THE following naturalists have been elected foreign members of the Linnean Society:-M. Adrien Franchet of Paris, Prof. Emil Christian Hansen of Copenhagen, Dr. Seiitsiro Ikeno of the Imperial University, Tokyo; Prof. Eduard von Martens of Berlin, and Prof. Georg Ossian Sars of Christiania.

THE gold medal of the Linnean Society, which was pre. sented at the anniversary meeting on May 24, has this year been awarded to Mr. John Gilbert Baker, of $\mathrm{Kew}$, in recognition of his important contributions to botanical science. Amongst these may be mentioned his Synopsis Filicum, his monographs of the daffodils and roses, handbooks on the Amaryllideae, Irideae, Bromeliceae, and the fern allies; three volumes on the Compositae in Martins's "Flora Brasiliensis," and several papers on Malagasy botany, the Flora of Mauritius and the Seychelles, the Bulbous Flora of the Cape, and the Leguminosae of British India, "Flora of the English Lake Country," and numerous papers communicated to the Journal of the Linnean Society, the Tournal of Botany, and other periodicals.

Ar the annual meeting of the Victoria Institute, to be held on June 19, an address will be delivered by Sir Richard Temple.

THE anniversary meeting of the Royal Geographical Society will be held on Monday next, June 5. The Society's annual conversazione will be held in the Natural History Museum on Wednesday, June 7 .

There will be no Friday evening discourse at the Royal Institution to-morrow (June 2), as Mr. H. G. Wells, who was to lecture on "The Discovery of the Future," is in too weak a state of health to do so.

Ar the recent annual meeting of the American Academy of Art and Sciences, Mr. Alexander Agassiz was elected president of the Academy. The Rumford medal was awarded to $\mathrm{Mr}$. Charles F. Brush, of Cleveland, for " the practical development of electrical arc lighting."

A Reuter telegram dated Helsingfors, May 26, says:"The collected pieces of the aerolite which fell at Bjurholm some time ago have been sent here, and placed in the geological museum. The largest piece is said to weigh 206 Russian pounds, while all the parts together weigh 850 lbs."

Dr. L. A. BAUer has resigned his position as assistant professor of mathematics and mathematical physics at the University of Cincinnati, in order to accept the position of chief of the newiy-formed division of terrestrial magnetism of the United States Coast and Geodetic Survey. To this division has been assigned the magnetic survey of the United States and the countries under its jurisdiction, and the establishment of magnetic observatories. Dr. Bauer has also been appointed lecturer in

NO. I 544 , VOL. 6o] 